\title{
ACUTE RESPIRATORY DISTRESS SYNDROME IN PREGNANCY
}

\author{
Madhumala H. R², Vikyath Jain², Rangalakshmi S³
}

\section{HOW TO CITE THIS ARTICLE:}

Madhumala H. R, Vikyath Jain, Rangalakshmi S. "Acute Respiratory Distress Syndrome in Pregnancy". Journal of Evolution of Medical and Dental Sciences 2015; Vol. 4, Issue 32, April 20; Page: 5600-5605,

DOI: $10.14260 /$ jemds/2015/820

ABSTRACT: Acute respiratory distress syndrome (ARDS) is a clinical syndrome of severe dyspnea of rapid onset, hypoxemia, and diffuse pulmonary infiltrates leading to respiratory failure. ARDS occurs in pregnancy and may have unique causes. Overall mortality for both the mother and the fetus is high and significant morbidity can persist even after initial recovery. ARDS is associated with obstetric causes such as amniotic fluid embolism, preeclampsia, septic abortion, and retained products of conception or non-obstetric causes that include sepsis, aspiration pneumonitis, influenza pneumonia, blood transfusions, and trauma. Here is a 24 years old female admitted with 7 months of amenorrhea, who presented with respiratory failure, she was intubated and ventilated for 47 days. She recovered, and a live baby was delivered. She was discharged after 73days.

KEYWORDS: Acute respiratory distress syndrome, Respiratory failure, Pregnancy.

INTRODUCTION AND BACKGROUND: Acute respiratory distress syndrome (ARDS) is a severe, often fatal, inflammatory disease of the lung characterized by the sudden onset of pulmonary edema and respiratory failure, usually in the setting of other acute medical conditions resulting from local (e.g. pneumonia) or distant (e.g., multiple trauma) injury.

Acute respiratory distress was initially described by Ashbaugh et al in 1967.(1) But there was difficulty in accurate diagnosis of these patients, so in 1992 The American-European Consensus Conference (AECC) on ARDS was formed in an effort to develop well defined clinical criteria for diagnosis.(2) (Table. 1)

A $45 \%$ mortality rate for patients on ventilator support has remained constant since mid1990s. It's as high as $90 \%$ if caused or complicated by sepsis. Although they are younger and healthier than the overall population, pregnant women still have mortality rate of 25 to 40 percent. $(3,4)$

CASE DISCUSSION: 24yrs old young Female, primigravida with 7months of amenorrhea presented with history of productive cough, difficulty in breathing at rest, fever from 5 days.

On examination she appeared anxious, uncomfortable but was awake, conscious and oriented, had tachycardia $(121 \mathrm{bpm})$, febrile (Temp-102F), tachypnea (34 breats/min), Hypoxia $\left(\mathrm{SpO}_{2}-88 \%\right)$ dyspnea, X-ray showed bilateral opacities. (Fig. 1)

She was admitted to MICU and ABG showed respiratory acidosis, Total Counts-18, 437, Hb-9. $5 \%$, PLT-1.7lak. Patient was intubated and put on ventilator IPPV mode with TV of $6 \mathrm{ml} / \mathrm{kg}$ with PEEP of 14, ventilated in supine position for 19days, intravenous antibiotics and steroids were given during this period of time. Initially she deteriorated, but after a week she improved and was weaned from ventilator and was extubated on the 20th day and shifted to antenatal ward for monitoring on oxygen mask. In the antenatal ward she developed breathlessness after 4 days and was shifted back to MICU as her respiratory status worsened, she was reintubated as X-ray showed left side lung opacities 


\section{CASE REPORT}

(Fig. 2), Sp02-85\%, Tachypnea, Tachycardia, and ABG showed respiratory acidosis. Intravenous antibiotics were started.

Fiberoptic Bronchoscopy with lavage was done, the lavage fluid was analyzed it showed predominant neutrophils, other parameters were unremarkable.

Patient was again ventilated in IPPV mode. After the X-ray resolved (Fig. 3) she was put on BIPAP mode. As her oxygenation improved she was later changed to CPAP mode and was weaned from mechanical ventilation on 43rd day. Once she was maintaining saturation on face mask, she was shifted back to ward. Patient had lost 9kg weight during this period, proper physiotherapy and good nutrition was provided.

She delivered at 37 weeks of gestation had a normal vaginal delivery and delivered a live male baby. She was observed and discharged from hospital after full recovery on $73^{\text {rd }}$ day with pulse94bpm, BP-120/68mmHg, $\mathrm{SpO}_{2}-99 \%$, Respiratory rate- 20breaths, She was asked to come for follow up one month later, which was again unremarkable.

DISCUSSION: Respiratory distress syndrome in pregnancy is uncommon, but when it occurs, it is a condition associated with catastrophic events. They are complex, with manifestations of multiple system involvement, it occurs mainly in the last trimester of pregnancy. The basic defect in ARDS is of oxygenation rather than of ventilation, as a consequence of widespread alveolar collapse with resultant ventilation perfusion mismatch and hypoxaemia.

Etiology: Here are few diseases associated with acute pulmonary injury and permeability edema during pregnancy:

- Pneumonia- Bacterial, Viral, Aspiration.

- Sepsis Syndrome- Chorioamnionitis, Pyelonephritis, Puerperal infection, Septic Abortion.

- Hemorrhage: Shock, Transfusion related acute lung injury (TRIAL).(5)

- Preeclampsia Syndrome.(6)

- Tocolytic therapy.

- Embolism- Amnionic fluid, Trophoblastic disease, Air.

- Connective tissue disease.

- Irritant inhalation and burns.

- Pancreatitis.

- Fetal surgery.

- Trauma.

- Miliary tuberculosis.

Sepsis accounts for majority of cases of ARDS with aspiration pneumonia (11\%), trauma (7\%), and pancreatitis (3\%).

MANAGEMENT: The management of the patients with ARDS is identification and treatment of underlying cause. ${ }^{(7)}$ with supportive care and monitoring the fetus for distress.

The functional residual capacity (FRC) is decreased that may lead to rapid decline in oxygen in response to any respiratory insult. There are more chances of metabolic acidosis because of sepsis and decreased compensation of respiration. 
There will be variety of hemodynamic changes with dilutional anemia, decrease in oncotic pressure, and soft tissue edema with risk of pulmonary edema. Cardiac output is also increased. There will be inferior vena cava compression after $20 \mathrm{wks}$ of gestation because of increase in size of uterus.

The important goal in ARDS should be to maintain adequate fetal oxygenation of $\geq 70 \mathrm{mmHg}$ which is corresponding to maternal $\mathrm{SaO}_{2}$ of $95 \%$.

Mechanical Conventional Ventilation: The criteria for intubation include tachypnea, decrease in GCS score, hemodynamic instability, inability to manage the airway, blood gas criteria, inability to maintain $\mathrm{PaO} 2$ of $>70 \mathrm{mmHg}$ or $\mathrm{SaO}_{2}$ is interpreted as sign of intubation.

Ventilation for the patient must be low pressure and low tidal volume, (8) to avoid ventilator associated lung injury. Tidal volume of $\leq 6 \mathrm{ml} / \mathrm{kg}$ body weight and plateau pressure of $\leq 30 \mathrm{cmH}_{2} \mathrm{O}$ should be maintained. Lower level of $\mathrm{PaO}_{2}$ should be avoided because placenta perfusion may be impaired.

Some severely ill patients who have developed oxygenation failure despite ventilation, need positive end expiratory ventilation, lung recruitment maneuvers, prone positioning, and inhaled nitric oxide, to improve oxygenation.

Positive end Expiratory Ventilation: it is successful to provide oxygen with ventilation pressure decreasing the shunt by recruiting collapsed alveoli at a low levels of 5 to $15 \mathrm{mmHg}$ which can be used safely.

Lung Recruitment Maneuvers: includes sustained inflation for 30-60sec at relatively high airway pressures of $40-50 \mathrm{mmHg}$ that may be employed during ventilation, to opening atelectasis alveoli and to improve oxygenation. (9)

In haled Nitric Oxide. In 1993 use of inhaled nitric oxide (I NO) to improve oxygenation in patients with ARDS was first reported.(10) Potential mechanisms of action, use in ARDS is based on its known properties as a selective pulmonary vasodilator with resultant improvement in ventilationperfusion matching.

Fetal Monitoring and Decisions Related to Delivery: Fetal assessment should take place and plan for delivery should be made. It depends on age of fetus, fetal status, maternal status and gestational age. Ultrasound is done for breathing movements, limb movements, heart rate variability, and amount of amniotic fluid which includes fetal urine.

Decisions Related to Delivery: Up to 32-34 wks. of gestational age, the premature fetus is generally better supported in utero than outside the womb. Given risk of inducing labor or performing a cesarean,(11,12) the indications for delivery should be the standard obstetric indications until more evidence is available regarding delivery.

CONCLUSIONS: The case we present was a challenge because she was in Hypoxemic respiratory failure resulting in ARDS during her pregnancy and was ventilated for 47days. 
Mechanical ventilation is essential in management of ARDS and low tidal volume with PEEP ventilation strategy is recommended. The longer patients are on ventilator, the greater the chance of complications, including airway injury from the tube and pneumonia.

Once the patient's ventilation requirement is decreased, patients are given a daily trial of breathing on their own to see if breathing is comfortable and adequate oxygenation is maintained.

The death rate associated with ARDS is usually high. Once a patient survives the acute episode of ARDS, their lung function gradually improves over six months to a year, with eventual return to normal lung function. Despite normal lung function in survivors, their quality of life is impaired frequently.

Early assessment of fetal wellbeing and plan of delivery are necessary to manage ARDS in pregnancy. It is important to optimize both maternal and fetal outcomes. Success in the outcomes of parturients with ARDS require clear and frequent communication between obstetricians and intensive care specialists.

\section{REFERENCES:}

1. Ashbaugh DG, Bigelow DB, Petty TL, et al: Acute respiratory distress in adults. Lancet 1967; 2: 319-323.

2. Wheeler AP, Bernard GR: Acute lung injury and the acute respiratory distress syndrome: a clinical review. Lancet 369: 1553, 2007.

3. Catanzarite V, Willms D, Wong D, et al: Acute respiratory distress syndrome in pregnancy and the puerperium: causes, courses, and outcomes. Obstet Gynecol 97: 760, 2001.

4. Cole DE, Taylor TL, McCullough DM, et al: Acute respiratory distress syndrome in pregnancy. Crit Care Med 33: S269, 2005.

5. Kopko PM, Marshall CS, MacKenzie MR, et al: Transfusion-related acute lung injury: report of a clinical look-back investigation. JAMA 287: 1968, 2002.

6. Sibai BM, Mabie BC, Harvey CJ, et al: Pulmonary edema in severe preeclampsia-eclampsia: analysis of thirty-seven consecutive cases. Am J Obstet Gynecol 156: 1174, 1987.

7. Deblieux PM, Summer WR: Acute respiratory failure in pregnancy. Clin Obstet Gynecol 1996; 39: $143-152$.

8. Ventilation with lower tidal volumes as compared with traditional tidal volumes for acute lung injury and the acute respiratory distress syndrome. N Engl J Med 2000; 342: 1301-1308.

9. Lim CM, Jung H, Koh Y, et al: Effect of alveolar recruitment maneuver in early acute respiratory distress syndrome according to antiderecruitment strategy, etiological category of diffuse lung injury, and body position of the patient. Crit Care Med 2003; 31: 411-418.

10. Rossaint R, Falke KJ, Lopez F, et al: Inhaled nitric oxide for the adult respiratory distress syndrome. N Engl J Med 1993; 328: 399-405.

11. Catanzarite V, Willms D, Wong D, et al: Acute respiratory distress syndrome in pregnancy and the puerperium: Causes, courses, and outcomes. Obstet Gynecol 2001; 97 (5 Pt 1): 760-764.

12. Tomlinson MW, Caruthers TJ, Whitty JE, et al: Does delivery improve maternal condition in the respiratory-compromised gravida? Obstet Gynecol 1998; 91: 108-111. 


\begin{tabular}{|c|}
\hline An Acute Onset \\
\hline $\mathrm{PaO}_{2} / \mathrm{FIO}_{2}$ ratio of $\leq 300$ \\
\hline Hypoxia score of $\leq 200$ regardless of PEEP \\
\hline Pulmonary artery occlusion pressure of 18mmHg \\
\hline Absence of clinical evidence of left arterial hypertension \\
\hline Bilateral infiltrates on chest radiography \\
\hline Table 1: AECC Clinical Criteria For ARDS Diagnosis \\
\hline
\end{tabular}

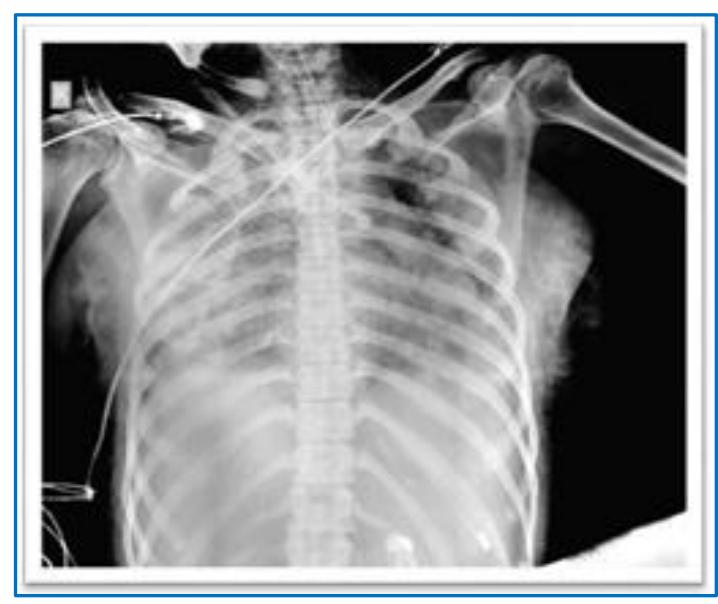

Fig. 1

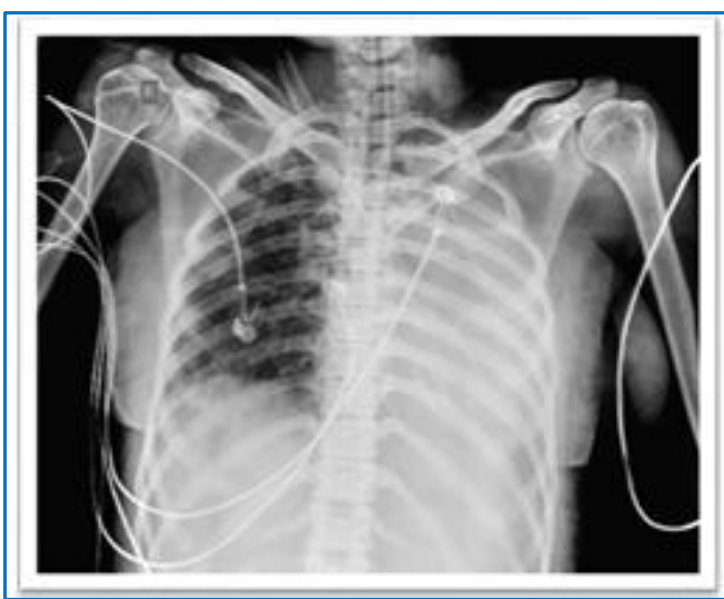

Fig. 2

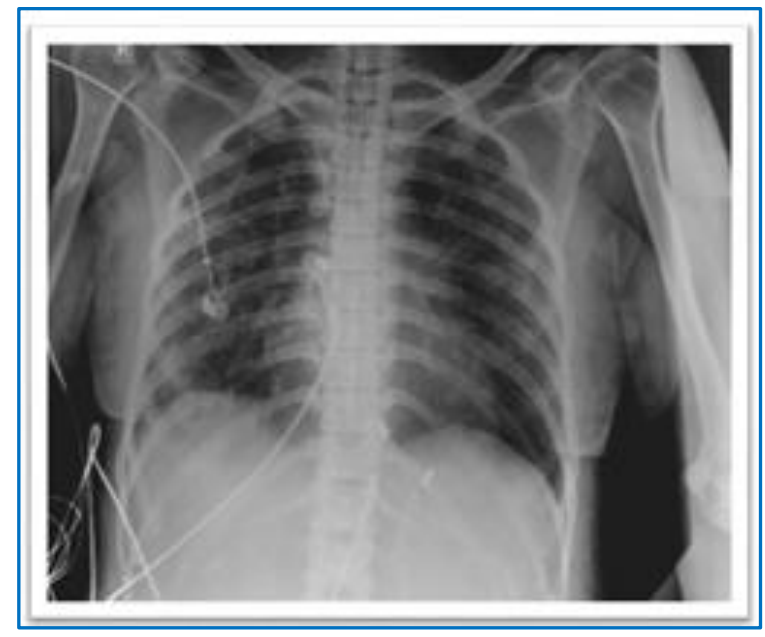

Fig. 3 


\section{AUTHORS: \\ 1. Madhumala H. R. \\ 2. Vikyath Jain \\ 3. Rangalakshmi S.}

\section{PARTICULARS OF CONTRIBUTORS:}

1. Assistant Professor, Department of Anaesthesia, RRMCH, Bangalore.

2. Junior Resident, Department of Anaesthesia, RRMCH, Bangalore.

FINANCIAL OR OTHER

COMPETING INTERESTS: None
3. Professor \& Head of Critical Care, Department of Anaesthesia, RRMCH, Bangalore.

\section{NAME ADDRESS EMAIL ID OF THE CORRESPONDING AUTHOR:}

Dr. Vikyath Jain, \# 21, $1^{\text {st }}$ Cross, GKW Layout, Vijayanagar,

Bangalore-560040.

E-mail: vikyath111@gmail.com

Date of Submission: 20/03/2015.

Date of Peer Review: 23/03/2015.

Date of Acceptance: 10/04/2015.

Date of Publishing: 20/04/2015. 